\title{
RELAÇÕES METODOLÓGICAS ENTRE FENOMENOLOGIA, HISTORIOGRAFIA E PSICOLOGIA HUMANISTA ${ }^{12}$
}

\author{
Methodological Relations among Phenomenology, Historiography and Humanistic Psychology \\ Relaciones Metodológicas entre Fenomenología, Historiografía y Psicología Humanística
}

WiLLIAM BARBOSA Gomes

\begin{abstract}
Resumo: Para o historiador, o método fenomenológico é recurso instrumental próprio à elaboração da difícil arte de narrar uma ação que efetivamente ocorreu. Para o psicólogo humanista, a fenomenologia é ferramenta para recuperar a riqueza vivencial enquanto fenomenalidades dadas à compreensão e à elucidação. Em nenhum dos casos a fenomenologia apresenta-se como perspectiva ou argumento, mas como recurso à exploração objetiva da subjetividade em busca de pistas intuitivas, mediadas pela lógica qualitativa. Primeiro, o artigo discorre sobre as discussões metodológicas em busca da conciliação entre a estética da narrativa e a necessidade de evidências, ocorridas nas origens da fenomenologia de Husserl. Segundo, toma a história da psicologia humanista para análise e para exemplo da dificuldade fenomenológica em discernir fato e valor, a chamada ambiguidade da experiência consciente. A ambiguidade é implícita ao discurso que se apresenta como a retórica de atribuir valor social à consciência da experiência. Conclui definindo historiadores e fenomenólogos como humanistas cuja tarefa é elaborar narrativas, mediadas por uma retórica ética, na qual a ambiguidade entre fatos e valores favoreça a evidência documental, tomando como regra de interpretação o tempo histórico e o espaço social.
\end{abstract}

Palavras-chave: Narrativa; Valor; Fato; Ambiguidade; Primeira pessoa.

\begin{abstract}
For the historian, the phenomenological method is an instrumental resource to draw up the difficult art of narrating an action that actually occurred. For the humanist psychologist, the phenomenological method is a tool to recover the living experience, as phenomenalities given to understanding and elucidation. In neither case, the phenomenology presents itself as perspective or argument, but as search for the objective exploration of subjectivity, looking at intuitive cues mediated by qualitative logic. First, the article comments the methodological discussions occurred at the beginning of the phenomenological theory on the conciliation of the aesthetics of narrative and the needs for evidence. Second, it takes the history of humanist psychology as an example to the phenomenological challenge in discerning fact and value, the so-called ambiguity of conscious experience. The ambiguity is implicit in the discourse that presents itself as the rhetoric of assigning social value to the consciousness of the experience. It concludes by setting historians and phenomenologists as humanist whose task is to prepare narrative, mediated by an ethical rhetoric, in which the ambiguity of facts and values are conducive to documentary evidence, taking as a rule of interpretation of the historical time and social space.
\end{abstract}

Keywords: Narrative; Value; Fact; Ambiguity; First person.

Resumen: Para el historiador, el método fenomenológico es un recurso instrumental para elaborar el difícil arte de narrar una acción que efectivamente ocurrió. Para el psicólogo humanista, la fenomenología es una herramienta para recuperar la riqueza vivencial, como fenomenalidad dada a la comprensión y elucidación. En ninguno de los casos la fenomenología se presenta como punto de vista o argumento, sino como un recurso para la exploración objetiva de la subjetividad en busca de pistas intuitiva, mediada por la lógica cualitativa. En primer lugar, el artículo describe los debates metodológicos en la busca de la reconciliación entre la estética de la narración y la necesidad de pruebas, pasadas en los orígenes de la fenomenología de Husserl. En segundo lugar, toma la historia de la psicología humanista como ejemplo para el análisis fenomenológico de la dificultad de discernir el hecho y el valor, la ambigüedad de la experiencia consciente. La ambigüedad está implícita en el discurso que se presenta como la retórica de la asignación de valor social a la conciencia de la experiencia. Se concluye estableciendo historiadores y fenomenólogos como humanistas cuya tarea es preparar a la narrativa, con la mediación de un discurso ético, en el que la ambigüedad de los hechos y los valores esteban más adecuados a las pruebas documentales, tomando como regla de interpretación los imperativos del tempo histórico y del espacio social.

Palabras-clave: Narrativa; Valor; Hecho; Ambigüedad; Primera persona.

\footnotetext{
O esse artigo é a junção de dois trabalhos apresentados no I Simpósio de História da Formação em Psicologia \& VIII Encontro da Rede Interinstitucional de Pesquisadores em História da Psicologia realizado em Belo Horizonte nos dias 2 e 3 de abril de 2009, como parte das comemorações dos 50 anos do Curso de Psicologia da Pontifícia Universidade Católica de Minas Gerais.

2 Tratando-se de estudo historiográfico será informado, sempre que possível, o ano de nascimento e morte de pensadores reconhecidos do movimento humanístico, indicados por colchete [...], também sendo informado a data original da publicação e da edição utilizada, por exemplo, Husserl (1931/2001).
} 


\section{Introdução}

O movimento fenomenológico (Spiegelberg, 1982), iniciado por Edmund Husserl [1859-1938] na virada do século XIX para o século XX, atravessa entrelaçamentos importantes com a historiografia e com o humanismo. Nos debates com o historiador Wilhelm Dilthey [1833-1911], Husserl compreendeu que a fenomenologia seria um rompimento com o positivismo, constituindo-se em um novo método para o estudo do conhecimento. Nos seus inícios, a psicologia humanista encontrou na fenomenologia européia introduzida nos EUA por Rollo May [1909-1994] nos meados século XX (May, Angel \& Ellenberg, 1958) fundamentos para as suas posições teóricas e alternativa metodológica para pesquisa (Giorgi, 1970)

O presente artigo focaliza as relações da fenomenologia com a historiografia e com o humanismo. Para o historiador, o método fenomenológico é recurso instrumental próprio à elaboração da difícil arte de narrar uma ação que efetivamente ocorreu. Para o psicólogo humanista, a fenomenologia é ferramenta para recuperar a riqueza vivencial enquanto fenomenalidades dadas à compreensão e à explicitação. Em nenhum dos casos, a fenomenologia apresenta-se como perspectiva ou argumento para interpretação, mas sim como recurso à exploração objetiva da subjetividade. Se essa conjunção seduz, também confunde, constituindo a ambiguidade que caracteriza o nosso encontro com a realidade (nômeno) e sua aparência à consciência (fenômeno). Psicoterapeutas e historiadores, humanistas por definição, estão diante de casos, seja de pessoas à procura de sentido para suas vidas, seja ações passadas para serem reconstituídas e interpretadas. O texto está organizado em duas partes. A primeira trata das afinidades metodológicas entre historiografia e fenomenologia. A segunda volta-se ao humanismo para analisar as sensíveis relações entre psicologia humanista e fenomenologia.

\section{Fenomenologia e Historiografia}

A primeira parte deste artigo concentra-se no problema da objetividade na narrativa histórica. Retoma e define a noção de historiografia, discute o problema da objetivação da história, para destacar as convergências metodológicas com a fenomenologia. Conclui indicando como a fenomenologia pode contribuir para a preparação de narrativas que respeite a evidência e a interpretação.

A arte de contar história confunde-se com a formação das primeiras civilizações. Histórias recolheram e constituíram valores que forjaram culturas, agruparam forças, definiram sentidos e criaram mitos. A crônica dos tempos e as histórias dos povos inspiram vidas, sustentam nações, e levantam esperanças em futuros materiais e imateriais. Lamentavelmente, a crônica dos tempos também alimenta o ódio e a destruição. A história é uma narrativa que descreve ações cuja veracidade pode ser real, imaginária, ou indefinida. Por conseguinte, a arte de contar história pode ser um discurso narrativo para descrever ações. Esse discurso recebe o nome de historiografia, e por descrever ações requer o apoio documental.

Os problemas inerentes à correspondência entre a narrativa e a ação sobre a qual se discursa levantaram grandes controvérsias (Toulmin, 1986). Os dois lados da controvérsia são conhecidos: 1) a epistemologia das ciências naturais que curiosamente não tem problema algum com a filosofia da ciência; e 2) a epistemologia das ciências humanas que infortunadamente tem tido muitos problemas com a filosofia da ciência. Na verdade, a distinção entre dados quantitativos e qualitativos (DeSouza \& Gomes, 2003) surge diante da objetivação do estudo da história por Leopold Ranke [1795-1886] na segunda metade do século XIX. Afinal, como disse John Stuart Mill [18061873], o princípio das ciências exatas deveria ser também aplicado às ciências morais. A esta tendência se insurge o historiador alemão Wilhelm Dilthey (1883/1990). Para ele, a natureza única e mutável dos eventos históricos exigia outra metodologia que não à utilizada pelas ciências exatas. Com a ressalva de que o caráter objetivo da narrativa deveria ser mantido.

Dilthey (1883/1980) chamou de "ciências do espírito" a totalidade das ciências que tem como objeto a realidade histórico-social. Entretanto, ele alertou que a expressão ciências do espírito, assim como outras já empregadas anteriormente, ciências da cultura na Alemanha ou ciências morais e políticas na França, têm o defeito de ser demasiado estreita com relação ao objeto proposto para estudo. Ele defendia a diferença de conteúdo entre as ciências do espírito e da natureza que vem acompanhada por uma diferença de métodos. As ciências do espírito se referem a um mesmo objeto - o gênero humano - e abrangem história, economia política, ciências jurídicas e políticas, e ainda estudo da religião, da literatura, da poesia, da arquitetura, da música, dos sistemas e concepções filosóficas do mundo e, finalmente, da psicologia. Todas elas trabalham com conceitos e teorias sobre fatos do gênero humano. Essas ciências descrevem e narram, julgam e formam conceitos. Em contraste, as ciências naturais têm como ideal a equivalência de causa e efeito, buscando a comparabilidade absoluta de magnitudes, cuja expressão mais acabada é a apreensão por meio de equações.

Na visão de Dilthey (1883/1980), as ciências do espírito, mesmo não estando baseadas em princípios tão claramente formulados como as ciências naturais, tinham fundamentos próprios e abrangentes e poderiam chegar a resultados objetivos. Dilthey, então, diferenciou a ciência em dois tipos. De um lado, a ciência explicativa que transcende os dados observáveis e elabora hipóteses. De outro, a ciência descritiva que se ocupa da classificação e sistematização dos fenômenos observáveis. Na época, a distinção radical entre ciências naturais e ciências históricas ou humanas rejeitava a tentativa, tanto do romantismo quanto do posi- 
tivismo, de reduzir todas as práticas científicas para uma única concepção epistemológica (Wolman, 1960).

Dilthey debatia suas posições com a escola neokantiana de Baden que era representada por Wilhelm Windelband [1848-1915] e por seu aluno Heinrich Rickert [1863-1936] e com a fenomenologia de Edmund Husserl (Spiegelberg, 1982). Os diálogos entre eles não foram fáceis. Windelband (1894/1980) não aceitava a alegação positivista da unidade entre as ciências. Foi ele que distinguiu as ciências empíricas pela característica lógica e não pelo conteúdo. O resultado foi a conhecida distinção entre as ciências referentes a leis universais, as nomotéticas; e as ciências referentes a eventos particulares, as ideográfica. Nesta classificação a psicologia foi considerada por Windelband como uma ciência natural, para garantir a validade atemporal da lógica do sujeito transcendental, baseando-se para tanto nas premissas kantianas das categorias a-priori, nas quais a diversidade empírica das sensações ganha sentido nas intuições puras como espaço e tempo. Trata-se do movimento entre realidade e percepção ou entre nômeno e fenômeno. Windelband entendia que assim estava preservando a certeza e a liberdade humana.

Para Rickert (1921/1986) que foi orientando de Windelband e que será o orientador de Martin Heidegger [1889-1976], a diferença entre ciências naturais e humanas era uma questão de valor. Para ele, todas as ciências deveriam ser orientadas por princípios éticos e para tanto deveriam gozar de plena liberdade, mesmo que fosse para examinar relações causais. Para ele, só em liberdade e acima das dependências causais o sujeito poderia reconhecer alguma coisa como significativa e verdadeira. Desta forma, um mesmo objeto poderia ser estudado na perspectiva da universalidade ou da particularidade.

Dilthey (1911/1992) não aceitou a posição idealista dos neokantianos, por considerá-la fundamentada em um valor a priori e absoluto, e nem a exigência de leis gerais quantificadas dos positivistas. Também não gostou da filosofia como ciência rigorosa de Husserl por entendêla como muito rígida. Por sua vez, Husserl não aceitou as críticas de Dilthey, acusando-o de querer fazer uma ciência sem rigor (Spiegelberg, 1982). Dilthey foi ainda criticado pelos sócio-históricos por não ter superado a ruptura cartesiana entre a subjetividade da história e a objetividade das ciências naturais. Reconheça-se, contudo, que Dilthey obteve êxito em substituir a razão histórica almejada pelos positivistas pela reflexão compreensiva dos hermeneutas. Para ele, as ciências humanas estão assentadas na experiência vivida (Erlebnis) que se constitui nos atos da expressão e da compreensão. Tal experiência é criativa e produz bens e valores.

O interesse pelo pensamento de Dilthey ressurgiu na década de sessenta (Amaral, 1987), por intermédio de renomados pensadores vinculados a tradição fenomenológica, tais como, Hans Georg Gadamer [1900-2002], com o célebre tratado "Verdade e Método" cuja primeira edição em alemão foi em 1960 e o fenomenólogo fran- cês Paul Ricoeur [1913-2005] com o também célebre "Interpretação" de 1965 e "Conflito das interpretações" de 1969. Em foco, o problema de como lidar com a reflexão compreensiva ou interpretação, uma contingência absoluta na vida de todos nós ou como diria Maurice Merleau-Ponty [1908-1961]: "Porque estamos no mundo, estamos condenados ao sentido, e não podemos fazer nada nem dizer nada que não adquira um nome na história" (1945/1999, p. 18, grifo do autor).

Compreender é interpretar. A interpretação é uma atribuição de sentido para o que se observa, seja uma fala, um texto, um ato, ou uma situação. É um processo ativo, sistemático, criativo e exploratório de possíveis sentidos (DeSouza \& Gomes, 2003). O termo sentido nos sugere a seguinte pergunta: qual o meio através do qual se oferecem mensagens para ser compreendidas? Pode-se responder juntamente com Merleau-Ponty (1999) que o sentido é um gesto transformado em linguagem.

A narrativa histórica se caracteriza por um processo ativo, sistemático, criativo e exploratório de possíveis sentidos. Dilthey (1911/1992) o resume em três etapas: descrição, julgamento e narrativa. A essa tríade, a fenomenológica apresenta-se como ferramenta ateórica que auxilia o historiador a não confundir seu sentido com os possíveis sentidos emergentes das ações descritivas (redução fenomenológica), fazendo da sua narrativa (interpretação) um exercício de compreensão (hermenêutica). Fenomenologia e historiografia são metodologias qualitativas que quando articuladas trabalham muito bem com dois conceitos epistemológicos (Lanigan, 1992): o apodíctico e o assertórico. Apodíctico refere-se ao que se mostra convincente em função das evidências. Assertórico refere-se que se afirma com base em uma ação passada, em conjunção às possíveis interpretações.

As técnicas fenomenológicas são eficientes no desvelamento da subjetividade, conduzindo nossa atenção crítica aos modos de apropriação do objeto (Gomes, 2007). Em termos cognitivos, vale-se da metacognição para acompanhar a tomada de consciência de um objeto, projetar a organização deste objeto e apresentá-lo nos termos indicados por Dilthey: uma descrição e um julgamento constituem uma narrativa.

\section{Fenomenologia e Psicologia Humanista}

A segunda parte deste artigo versa sobre as relações entre fenomenologia e psicologia humanista, em particular ao enunciado "Psicologia humanista e fenomenologia: uma história sobre a legitimação da experiência humana.” ${ }^{3} \mathrm{O}$ enunciado proposto é um convite ao diálogo com a história, no qual se recorrerá à fenomenologia

\footnotetext{
O tema proposto por Miguel Mahfoud (UFMG) para Mesa Redonda no I Simpósio de História da Formação em Psicologia \& VIII Encontro da Rede Interinstitucional de Pesquisadores em História da Psicologia que contou também com a participação de Vera Engler Cury (PUC-Campinas).
} 
como recurso de análise. O método fenomenológico nos ensina que uma boa maneira de iniciar uma análise é pela ordem contrária do enunciado (Lanigan, 1988). Sendo o enunciado "uma história sobre a legitimação da experiência”, a análise vai começar pela experiência humana, para em seguida considerar a legitimação desta experiência e por fim situá-la na história. Temos então três termos para análise, nesta ordem: 1) experiência humana, 2) legitimação, e 3) história.

Experiência, como sabemos, é o conhecimento direto, intuitivo que temos dos fatos ou dos fenômenos sejam eles referentes ao presente, ao passado ou ao futuro. $\mathrm{O}$ termo humano agrega a experiência um sentido único e superior: a capacidade de se referir em discurso a esse conhecimento. Animais têm experiência. Eles sofrem com a dor, com a fome, com o maltrato, expressam alegria com maior ou menor expansão, eles são capazes de reconhecer outros animais, de reconhecer humanos, de reconhecer lugares, tendo, portanto: memória, capacidade associativa, presteza na tomada decisão, manifestação de solidariedade, e de companheirismos. Contudo, os animais não discursam e, em não discursando, não nos dizem diretamente o que pensam ou sentem. Eles não fazem história e não representam os signos da experiência.

O humano desponta como aquele que faz da experiência o enigma de sua história e o conteúdo do seu discurso. Foi a consciência dessa experiência que o fez reconhecer a morte, sentir a falta, imaginar o futuro, e acima de tudo, de se expressar através de símbolos exteriores, cujos primeiros exemplos foram os sinais rupestres e a construção de túmulos. A riqueza da experiência, no sentir e no viver o presente, certamente acendeu o desejo de eternidade. Uma eternidade material no desenvolvimento da arte ilustrativa e da história épica. Uma eternidade espiritual na construção de mitos, na invenção de outra vida para o além, na redução a rituais religiosos e tabus. A experiência humana aqui se registra como algo que dá forma, que faz aproximar e identifica; mas que também separa uma cultura de outra cultura, um grupo de outro grupo, uma etnia de outra etnia, uma religião de outra religião (ver Gomes, 2004).

Foi essa experiência humana (Mueller, 1960) que desenvolveu a linguagem, que escreveu as grandes histórias fundadoras nos textos sagrados e nos textos épicos. Esses escritos estabelecem as bases de uma cultura e o amálgama de um povo. Foi a dúvida com as impressões oriundas da experiência que exigiu a racionalidade para explicar a natureza, mas se confundiu com a diversidade, aprendendo a lidar com ela por meio de sofismas. Sofisma é o artifício do argumento. Vence quem sabe argumentar. As contradições dos sofismas trouxeram a questão da virtude, do respeito ao outro e da importância do conhecimento de si mesmo. Do cogito sobre essas questões vieram a filosofia, a matemática, a escultura, o teatro, a música, a arquitetura; enfim, os grandes exercícios do intelecto, e do domínio da natureza pelos huma- nos. Neste fluxo de realizações despontavam: 1) a força criadora e autoexpressiva dos humanos, e 2) a luta pela preservação da liberdade e do poder.

É difícil pensar neste fluxo de reflexões e de expressões da inteligência humana como uma força unitária. Ela se compõe de muitas camadas que formam contrastes e realçam focos. São sincronias que se estruturam como marcas do tempo. Mesmo assim, há um movimento que segue seu rumo e que depois o interpretamos como história. Esse movimento é diacrítico, seguindo como uma noite depois de um dia, uma época depois de outra época, uma letra depois da outra, e assim por diante (Barthes, 1964/1971). É uma passagem, uma estrada sem retorno.

É neste movimento diacrítico que a história nos aponta para as oscilações dos indicadores mais profundos da expressão humana: supressão das liberdades reflexivas e autoexpressivas, inibição do pensamento, aprisionamento. A supressão ocorre quando os humanos são induzidos ou convencidos a aceitar que outros pensem por ele. Por conseguinte param de pensar por si mesmos. Quando se chega a esse ponto, há que se resgatar o humano e restabelecer o seu poder criativo. A renascença exerceu esse papel de resgate e por isto foi considerada uma manifestação humanista (Hearnshaw, 1987). Ela se inspirou, como sabemos, nos gregos e nos romanos para restabelecer o saber crítico voltado para um maior conhecimento do homem e capaz de desenvolver as potencialidades da condição humana. Era o início da modernidade, marcada pelo esforço de Descartes [1596-1650] em descobrir um método para encontrar respostas sem depender da revelação, essa força sobrenatural que guiou o pensamento na idade média. Aliás, nada há de mais pós-moderno do que o método de Descartes, que nos diga as Meditações Cartesianas de Husserl (Husserl, 1931/2001). Infelizmente, Descartes é mais lembrado pelos seus desacertos do que pelos seus muitos acertos. Podemos passar agora para a análise do segundo termo: legitimação.

O método de Descartes (1637/1985) é o caminho para legitimação da experiência humana. A pergunta básica de Descartes é simples e direta. Do conhecido bordão, penso logo existo, se pode extrair duas lições fenomenológicas. $\mathrm{O}$ penso logo existo refere-se à consciência direta e imediata da experiência. Contudo, o salto cartesiano, o seu brilho inigualável, está na segunda lição fenomenológica do bordão: Como posso confiar na consciência da minha experiência? Em outras palavras o que é a minha existência? Estava posta a dúvida metódica: o meio para a ampliação da experiência humana, pelo desenvolvimento do conhecimento. Por isso, o existo logo penso de Jean-Paul Sartre [1905-1980] é uma contradição, pois o saber que existo pressupõe o eu penso. Eu tenho que ter consciência para sentir que existo que estou vivo (ver Sartre, 1943).

A breve visita a Descartes nos dá a oportunidade de exercitar um recurso básico de análise, denominado de suspensão fenomenológica. Nesta suspensão, algumas questões são colocadas de lado para que se possa cuidar 
mais atentamente de outras. Assim, podemos suspender as implicações cartesianas da relação mente-corpo, para nos concentrar nas relações mente-mente. A análise dirige-se agora para o movimento crítico que diferencia o conhecimento novo do conhecimento velho: a transformação da experiência consciente em consciência da experiência. Aqui ocorre outra suspensão. Eu deixo de me interessar pelo crescimento fantástico e revolucionário da experiência humana, na forma de conhecimento científico, tecnológico, filosófico, artístico e literário, para lidar com as incertezas da crença em minhas próprias experiências.

Por relação mente-mente indica-se a transformação da experiência consciente em consciência da experiência. A experiência consciente é o momento da vivência. Por exemplo, neste auditório nós vivenciamos esse momento ao nos sentirmos entre muitas pessoas, no conforto ou desconforto das cadeiras, no calor ou no frio que faz na sala, no dividir a atenção entre ouvir aquele que fala e olhar para aquela pessoa que esta ali na minha frente; no sentir a falta de alguém que eu queria encontrar aqui, mas que não vejo; ou melhor, na surpresa inesperada de ver alguém que eu queria muito ver e está aqui tão perto, que já não consigo mais ouvir quem fala, pois não consigo parar de pensar nela. Note que nesta variação imaginária apresentou-se uma ficção, realçando a força que nos move e sem a qual não seríamos nada: as emoções e os sentimentos.

A relação mente-mente volta-se ao vivido, essa conjunção de sentimentos e idéias, ou da idéia movida pelo sentimento, do sentimento paralisado pela idéia, ou da idéia barrada pelo sentimento. A compreensão de que idéias e sentimentos se regem pelos mesmos princípios está em Baruch Espinosa [1632-1677] e em GottfriedWilhelm Leibniz [1646-1716], dois dos grandes pensadores racionalistas. Eles foram os primeiros a descrever a interdependência entre a vida intelectiva e afetiva (Hearnshaw, 1987). O conflito entre sentimentos e idéias no limiar da nossa consciência foi uma descoberta de Friedrich Herbart [1776-1841], o grande pedagogo alemão (Klein, 1970). Neste ponto podemos trazer de volta a relação mente-corpo, porque sem corpo não há afetos e sem afetos não há movimento, nem mesmo nas abstrações reflexivas que mesmo lógicas são movidas por afetos (Aristóteles [384-322, a.C], 2006)

As considerações apresentadas sobre a experiência humana foram genéricas. É preciso ir adiante e tratar da experiência humana particular. Não interessa aqui o caminho da medida psicofísica, colocada também entre parênteses pela suspensão fenomenológica. Sabemos da importância das sensações para o nosso intelecto e assim vamos assumir teoricamente que elas estão em boas condições de captar a experiência que nos envolve nesse momento. Vamos nos concentrar nesse fluxo de experiências, no que há de mais humano e particular, para deixar sair essa ebulição desconcertada de idéias e de sentimentos. Com força e vontade podemos colocar tudo isso para fora, puxando com força, mesmo que com lágrimas de doces alegrias ou de tristes ais. Visto de frente, poderemos dar início à compreensão dos fatos da consciência. Foi esse o caminho escolhido por Henri Bergson [1859-1941] na procura do método para trabalhar com os dados da consciência. O esforço, contudo, não se mostrou venturoso. Franz Brentano [1838-1917] talvez tenha tido mais sorte que Bergson, apostando na descrição da experiência e em uma psicologia argumentativa.

Na verdade, a descrição é sempre o primeiro passo, há que se examinarem as possíveis relações entre os diversos elementos de uma ação. Como história, cabe lembrar debates que se aparentemente levaram a diferentes teorias e sistemas, no fundo estavam esclarecendo a natureza do fenômeno psicológico. Na Alemanha, um grupo de estudiosos da psicologia na Universidade de Berlim realizou a notável descoberta de que as relações causais, além de lineares, eram também curvilineares. O sentido tanto poderia ser consequência de relações causais, arbitrárias ou não, quanto de relações configuracionais, reversivas ou não. Estou falando das leis da Gestalt. Ainda na mesma Alemanha, na Universidade Hale, o matemático Husserl, influenciado por Brentano, sustentava a tese de que a base filosófica para a lógica e para a matemática deve começar pela análise da experiência que precede ao pensamento formal. Em outros termos, a compreensão da experiência humana particular requer, em primeiro lugar, uma descrição livre de qualquer juízo. A suspensão do juízo era a exigência para que as portas se abrissem ao novo. Contudo, o novo não seria uma imposição, nem gozaria domínio absoluto. Ele seria examinado exaustivamente para a descoberta das implicações lógicas da sua natureza e então compreendido. Estão aí os três passos básicos da fenomenologia, que começa por um sentimento de abertura à experiência, atravessa os escrutínios intuitivos e lógicos do pensamento investigativo, para elucidar o próprio pensamento, como propunha a fenomenologia transcendental de Husserl ou então descobrir e decidir por novos valores e suas implicações, de acordo com o entendimento da fenomenologia existencial (Gomes, 2007).

As obras literárias são também descrições de experiências humanas e da experiência particular de um escritor. Dos literatos russos veio à preocupação de especificar o fato literário em si, livre de compromisso moral, filosófico ou mesmo psicológico. Para eles, a emoção enquanto fato literário era decorrente do jogo das palavras. Esse método formal de crítica literária ampliou-se em Praga, com a idéia de sistema. $\mathrm{O}$ fato literário não era um aspecto isolado, mas parte de um sistema social mais amplo. Esses movimentos contribuíram para a noção de que não só a linguagem, mas a sociedade e a cultura estão constituídas por relações estruturais, organizadas em sistemas com regras próprias (Nöth, 1995).

A suspensão do juízo e a análise formal das relações estiveram presentes de algum modo na descrição de povos muito antigos encontrados em ilhas distantes ou em densas florestas à beira de grandes rios. Na acuidade descritiva 
estaria a necessidade de decifrar modos e costumes para compreender e dar a compreender o novo de cada cultura e as possíveis similaridades entre as muitas culturas e seus produtos, entre elas as narrativas mitológicas. Foi o que nos ensinou os etnólogos (Malinowski, 1922/1976).

Em síntese, há uma confluência ontológica extraordinária entre o caos fenomenal que intrigou Bergson e Husserl. No entanto, Bergson (1889) não conseguiu se livrar do caos, enquanto Husserl (1931/2001) nos propôs um método para trabalhar com a consciência imediata. Contribuições para o estudo da consciência também vieram da linguística estrutural de Ferdinand de Saussure (1857-1913) e dos formalistas russos com a apropriação criativa e expansiva da Escola de Praga. As línguas foram definidas como sistema no qual cada um dos elementos só pode ser definido pelas relações de equivalência ou de oposição que mantém com os demais elementos. A semiologia, uma decorrência da linguística estrutural, influenciou a literatura de ficção, a antropologia, a música, o teatro, o cinema e a psicanálise (Nöth, 1995).

Esclarecida a condição ontológica, vamos examinar a condição ética da experiência humana para abordar a sua legitimação e então podemos situar os campos da psicologia humanista e da fenomenologia. Fenomenologia é um método para guiar o pensamento, para diferenciar epistemologia (o imediato) de psicologia (o mediato). A epistemologia pergunta pela veracidade da experiência nova. A psicologia debate-se com as valorações e suas contradições na experiência velha. Com o método fenomenológico ou sem ele, estamos sempre lidando com esse dilema em nossa consciência. Uma tarefa da consciência de cada um de nós. Em contraste, o humanismo, como nos ensinou os articuladores do renascimento, é o enaltecimento das potencialidades humanas.

Por conseguinte, a psicologia humanista é uma ética para o enaltecimento das potencialidades, da integralidade holística, da liberdade e da autonomia (Schneider, Bugental, \& Pierson, 2002). É uma ética pela autenticidade que é a reavaliação continuada da experiência de si. Os velhos valores não podem abafar a novidade, mas o novo não deve destruir o velho. A boa civilização e a civilidade se sustentam no diálogo crítico e atualizado entre o velho e o novo. A autenticidade é essa clareza de metas pessoais, sentida e encarnada em um encontro entre fala e corpo. A fala consubstanciando clareza de pensamento em corpo ativo, pujante de emoções e sentimentos: a autêntica existencial. É simplesmente isto, pois qualquer ideia de um eu escondido dentro de mim é vã. Como sabemos, foi a apropriação do existencialismo de Søren Kierkegaard [1813-1855] pela fenomenologia de Heidegger (1927/1989) que vislumbrou uma fenomenologia da existência.

Enquanto ética, o humanismo é nas palavras do filósofo dinamarquês Ferdinand C. S. Schiller [1864-1937] o retorno à máxima sofista que a experiência humana é a medida de todas as coisas. Mas Schiller (1907/2005), foi cartesiano, pois para ele o humanismo era uma fórmula para tornar as idéias claras e acabar com os exageros e subtilezas verbais da filosofia. Segundo historiadores (Misiak \& Sexton, 1973) foi Abraham Maslow [1908-1970] que deu início ao movimento humanista na psicologia, com o seu livro Motivação e Personalidade em 1954. A esse movimento uniram-se grandes terapeutas como Carl Rogers [1902-1987] e Rollo May. Em 1961 saiu o primeiro número do Journal of Humanistic Psychology. No entanto, o grande porta-voz do movimento foi Clark Moustakas e os títulos de dois dos seus trabalhos seminais elucidam a tese humanista. O livro que ele organizou em 1956 com o título "Self: Explorações do crescimento pessoal", e um artigo de 1985 publicado, justamente no Journal of Humanistic Psychology, no qual diferencia humanismo de humanístico. Na verdade, um dos argumentos desta exposição. A última etapa dessa análise é tomar a história como objeto de reflexão.

Para falar de história é preciso pedir licença para interpretar e teorizar. Análises históricas requerem critérios lógicos e, portanto, escolhas éticas que podem ser bem ou mal sucedidas. Escolhi dois critérios semióticos para ilustrar as relações entre fenomenologia e humanismo na história da psicologia (Barthes, 1964/1971). O primeiro critério é a característica diacrônica da narrativa, a ordem dada à descrição dos elementos que constituem a historicidade. A segunda característica são as variações de foco sobre elementos histórico de uma mesma época, que correm em linhas simultâneas. A historiografia, a arte de contar história (e aconteceu e aconteceu), é uma seleção entre elementos que se intercruzam (u desse jeito ou daquele jeito), sendo esse intercruzamento decorrente das substituições de elementos das linhas e perspectivas que correm simultaneamente. Empresto esses critérios da semiótica, a ciência das ciências, por estudar a formação e a função de sistemas conceituais e empíricos que sustentam nossas certezas provisórias. Aliás, essa é a máxima da ciência. A ciência não é a verdade, é a razão dos resultados sobre a minha teoria, é apenas uma conclusão momentânea. São as incertezas que nos levam à revisão continuada das nossas crenças e que fazem da ciência uma prática transparente e democrática. Tais características têm sido criticadas por setores da sociologia da ciência, como herança do puritanismo anglosaxônico (por exemplo, Latour, 1985; Merton, 1973). Na verdade, ideias puritanas impulsionaram movimentos que levantaram a valores democráticos no século XVIII, assemelhando-se, em certo sentido, à revolução francesa e, com certeza, à fundação da república dos EUA. Por sua vez, ciência só encontra solo fértil em espaços consagrados pela democracia. Do mesmo modo, a ciência não tem afinidades com aqueles que estão absolutamente certos de suas verdades.

O exercício lógico desta exposição é caracterizar o humanismo como uma ideologia cíclica e romântica na busca da atualização de valores para a defesa da delibe- 
ração poética e irrefletida da vontade. Enquanto busca de valores, esteve presente na Grécia antiga, no renascimento, na prospecção por justiça social, no individualismo da autorrealização, e recentemente nos estridentes movimentos em defesa do verde, do planeta sustentável, e da subjetivação psicológica. Ao contrário, enquanto enaltecimento das realizações humanas defende: a racionalidade, a ciência e a tecnologia. Enquanto defesa de essências humanas é oposto às noções de medidas, à identificação dos contrários, ao rompimento de barreiras e limites, e à tecnologia. Interessa-se pela história ou partes da história, pelo encoberto, e pelo enaltecimento dos afetos (Löwy \& Sayre, 1995).

Quando a busca humanista de querer-ser dar lugar ao querer-fazer, o sujeito que escolhe é tomado pela escolha e o objeto por valores assumidos. Por conseguinte, a ação irrefletida transforma-se em mitologia. Essa virada é difícil e preocupante para o cientista e o profissional, mas inspiradora para o militante, qualquer que seja ele (Greimás, 1976).

Ao contrário, a fenomenologia é uma resposta às dificuldades operacionais para o estudo empírico do dado psicológico primeiro: apreensão de qualidades empíricas em signos impregnados de sentidos: a experiência humana. O signo não é uma construção e nem a atribuição de um conteúdo a uma forma. O signo é a paráfrase que formula de outra maneira o conteúdo equivalente. A fenomenologia é o estudo dessa substituição, dessa capacitação natural humana, movendo-se, para tanto, da préreflexão à metarreflexão, por recursos indutivos e lógicos. Por isso se diz que em última instância a fenomenologia é um método que nos ensina a pensar.

Diante do exposto, a incrível proximidade e distância entre humanismo e fenomenologia se esclarecem facilmente. O humanismo é um investimento em modelos que aparecem como potencialidades de processos, mas vazios de substâncias. Não se pode falar em uma filosofia humanista e mesmo de uma psicologia humanista. Com efeito, fala-se em movimento humanista pelo grande espectro de valores agregados. Numa perspectiva semiótica, o humanismo é uma articulação sintagmática. Em contraste, a Fenomenologia é uma filosofia que investiga valores organizados em sistemas, define taxonomias e descobre estruturas semióticas ou substâncias. É, portanto, uma articulação paradigmática. Como a historiografia é uma tarefa ambígua e decorrente dos encontros e desencontros entre fluxos sintagmáticos e paradigmáticos, as relações entre humanismo e fenomenologia são confusas e às vezes equivocadas.

\section{Epílogo}

O presente artigo analisou três conceitos: historiografia, fenomenologia, e humanismo/psicologia humanista. Na prática, tomou a fenomenologia como fundamento para uma breve historiografia da psicologia humanista. Historiografia foi definida como uma narrativa que interpreta ações humanas, vinculadas ao tempo, com o uso de lógica qualitativa e da retórica. A validação da narrativa se faz por meio de revisões críticas. Fenomenologia foi definida como um fundamento para a análise factual da experiência humana (apodíctico), isto é, a análise da consciência da experiência enquanto fatos expressos em linguagem (narrativa). A validação da análise se faz pelo movimento reflexivo sistêmico e sistemático, por exemplo, descrição, redução e interpretação. A psicologia humanista foi definida como uma ética voltada ao resgate livre e pleno da autoexpressão humana, com os objetivos: 1) de facilitar as relações interpessoais, organizacionais e internacionais, e 2) de incrementar a apropriação crítica e produtiva da experiência vivida enquanto individualidade e coletividade. Enquanto ética, a psicologia humanista é um discurso cuja legitimação é uma convenção firmada por consenso. Consenso é constituído pela confluência de valores: maior confluência - maior o consenso. Mudam-se os tempos, mudam-se os valores e os consensos. Essa é a problemática que aflige na atualidade os remanescentes dos movimentos humanísticos e que ilustra a preocupação da análise oferecida pelo presente artigo.

Estudiosos da psicologia humanista (por exemplo, Elkins, 2009; Cain, 2003) estão preocupados com o declínio do poder e da influência da psicologia humanista. $\mathrm{O}$ apodíctico, isto é, a facticidade indica, segundo os autores, que a psicologia humanista vem perdendo membros de suas associações e representantes entre professores e pesquisadores nas universidades. Para prosseguir com a análise, tomemos a facticidade indicada como descrição dessa ação, isto é, do status da psicologia humanista nos EUA. No julgamento de Cain (2003), a situação atual está associada à escassez de pesquisa com base em critérios da ciência natural, à ausência de artigos nas principais revistas, à dificuldade de promover e manter organizações fortes, e à incapacidade de se livrar de estereótipos justos ou injustos incorporados ao longo do tempo. No julgamento de Elkins (2009, p. 271), tal facticidade se deve ao conservadorismo que vem dominando a sociedade americana. Para ele, a revolução humanista dos meados do século XX esvaneceu-se e a psicologia americana é hoje muito mais "mecanicista, reducionista, determinista e anti-humanista" do que antes. Ele conclui dizendo que a psicologia humanista deve retomar sua tradição e confrontar os desacertos da psicologia contemporânea.

Temos então um consenso descritivo e um desacordo de julgamento. O problema que nos resta é como oferecer uma interpretação ao caso. É neste momento que fatos e valores se confundem na consciência do analista e sua interpretação será uma retórica na qual se atribui um valor social a um comportamento explícito (as posições de Cain [2003] e de Elkins [2009]). O discurso decorrente será uma ética cujo campo é a boa ou a má ambiguidade. A regra de interpretação é que a ciência, a despeito de 
uma sucessão de erros e acertos, avança por apropriação do que se mostra efetivo na especificação de processos e modos de intervenção. Recursos para sobrevivência e satisfação social modificam-se e geram novas demandas. Congelar um modo de intervenção, como quer Elkins, é estacionar no tempo. No entanto, esse discernimento falta ao romântico, mas sua insurgência atende a função social de equilíbrio e convivência entre os povos, mesmo que as soluções não estejam nos exageros de suas propostas. $\mathrm{O}$ status atual da ciência psicológica, quando conceitos de ciência natural e de ciência humana dão lugar a conceitos de dados de primeira e de terceira pessoa, parece corresponder a visão de Rickert (1921/1986). Para o filósofo, já mencionado, só em liberdade e acima das dependências causais o sujeito poderá reconhecer alguma coisa como significativa e verdadeira (ética humanista). Desta forma, espera-se que um mesmo objeto poderá ser estudado na perspectiva da universalidade (nomotético) ou da particularidade (idiográfico). As exigências e compromissos sociais da atualidade, uma conquista de movimentos humanistas, são hoje bem maiores do que nos meados do século XX o que requer uma ciência mais apurada em suas práticas e mais atenda aos princípios éticos.

\section{Referências}

Amaral, M. N. (1987). Dilthey: Um conceito de vida e uma pedagogia. São Paulo: Editora Perspectiva.

Aristóteles (2006). De anima (M. Reis, Trad/Ed). São Paulo: Ed 34.

Barthes, R. (1971). Elementos de semiologia (I. Blikstein, Trad.) São Paulo: Cultrix. (Originalmente publicado em 1964).

Bergson, H. (1889). Essai sur les données inmédiates de la conscience (39 a Edition) Paris: PUF.

Cain, D. J. (2003). Advancing humanistic psychology and psychotherapy: Some challenges and proposed solutions. Journal of Humanistic Psychology, 43(3), 10-41.

Descartes, R. (1985). Discurso do método: Apresentação e comentários de Denis Huisman (E. M. Marcelina, Trad.). Brasília: Editora da Universidade de Brasília. (Originalmente publicado em 1637).

DeSouza, M. L., \& Gomes, W. B. (2003). Evidência e interpretação em pesquisa: As relações entre qualidades e quantidades. Psicologia em Estudo, 8(2) 83-92.

Dilthey, W. (1980). Introducción a las ciencias del espíritu. (J. Marías, Trad.). Madrid: Alianza Editorial. (Originalmente publicado em 1883).

Dilthey, W. (1992). Teoria das concepções do mundo (A. Morão, Trad.). Lisboa: Edições 70. (Originalmente publicado em torno de 1911).

Elkins, D. N. (2009). Why humanistic psychology lost its power and influence in American Psychology: Implications for advancing humanistic psychology. Journal of Humanistic Psychology, 49(3), 267-291.

Gadamer, H-G. (1998). Verdade e método (F. P. Meurer, Trad.). Petrópolis: Vozes. (Originalmente publicado em 1960).

Giorgi, A. (1970). Psychology as human science: A phenomenologically based approach. New York: Harper \& How.

Gomes, W. B. (2004). Primeiras noções da psique: das concepções animistas às primeiras concepções hierarquizadas em antigas civilizações. Memorandum, 7, 32-46.

Gomes, W. B. (2007). Distinção entre procedimentos técnico e lógico na análise fenomenológica. Revista da Abordagem Gestáltica, XIII(2), 228-240.

Greimás, A. J. (1976). Sémiotique et sciences sociales. Paris: Seuil.

Hearnshaw, L. S. (1987). The shaping of modern psychology. London: Routledge

Heidegger, M. (1989) Ser e tempo (M. S. Cavalcanti, Trad.). Petrópolis: Vozes. (Originalmente publicado em 1927).

Husserl, E. (2001). Meditações cartesianas: Introdução a fenomenologia (F. Oliveira, Trad.). São Paulo: Madras. (Originalmente publicado em 1931).

Klein, D. B. (1970). A history of scientific psychology: Its origins and philosophical backgrounds. New York: Basic Books.

Lanigan, R. (1988). Phenomenology of communication: MerleauPonty's thematics in Communicology and Semiology. Pittsburgh: Duquesne University Press.

Lanigan, R. (1992). The human science of communicology. Pittsburgh: Duquesne University Press.

Latour, B. (1985) Les vues de l'esprit': Une introduction à l' anthropologie des sciences et des techniques. Culture Technique, 14, 5-29.

Löwy, M., \& Sayre, R. (1995). Revolta e melancolia: O romantismo na contramão da modernidade (J. Teixeira, Trad.). Petrópolis: Vozes. (Originalmente publicado em francês, 1992).

Malinowski, B. (1976). Argonautas do pacífico ocidental: Um relato do empreendimento e da aventura dos nativos nos arquipélagos da Nova Guiné Melanésia (Coleção Os Pensadores; vol. 43), (A. P. Carr \& L. Mendonça, Trads.). São Paulo: Abril Cultural. (Originalmente publicado em 1922).

Maslow, A. (1954). Motivation and personality. New York: Harper \& Row.

May, R., Angel, E., \& Ellenberg, H. F. (Eds.). (1958). Existence: A new dimension in psychiatry and psychology. New York: Simon \& Schuster.

Merleau-Ponty, M. (1999). Fenomenologia da percepção. (C. A. Ribeiro de Moura, Trad.) São Paulo: Freitas Bastos. (Originalmente publicado em francês, 1945).

Merton, R. K. (1973). The Sociology of Science. Chicago: Univ. of Chicago Press. 
Misiak, H., \& Sexton, V. S. (1973). Phenomenological, existential, and humanistic psychologies: A historical survey. New York: Grune \& Stratton.

Moustakas, C. E. (Ed.). (1956). The self: Explorations in personal growth. New York: Gurne \& Stratton.

Moustakas, C. E. (1985). Humanistic or humanism? Journal of Humanistic Psychology, 25(3), 5-12.

Mueller, J-L (1960). Histoire de la Psychology de l'antiguité à nous jours. Paris: Payot.

Nöth, W. (1995). Handbook of semiotics. Bloomington: Indiana University Press.

Ricoeur, P. (1965). Linterprétation. Paris: Seuil.

Ricoeur, P. (1978). O conflito das interpretações: Ensaios de hermenêutica (M. F. Sá Correia, Trad.). Rio de Janeiro: Imago. (Publicado originalmente em francês em 1969).

Rickert, H. (1986). The limits of the concept formation in natural science: A logical introduction to the historical sciences (G. Oakes, Trad.). Cambridge, UK: Cambridge University Press. (Originalmente publicado em alemão, em partes, 1896, 1902 e 1921).

Sartre, J. P. (1943). L' Être et le Néant. Essai d’ ontologie phénoménologique. Editions Gallimard: Paris.

Schiller, F. C. S. (2005). Studies in humanism. New York: Elibron Classics. (Originalmente publicado em 1907).

Schneider, K. J., Bugental, J. F. T., \& Pierson, J. F. (2002). The handbook of humanistic psychology. Thousand Oaks: Sage Publications Ltd.

Spiegelberg, H. (1982). The phenomenological movement. The Hague: Martinus Nijhoff Publishers.

Toulmin S. E. (1986). Philosophy of Science. Em The new encyclopedia Britannica (p. 660-678). Chicago: Encyclopedia Britannica.

Windelband, W. (1980). History and Natural Science. (G. Oakes, Trad.). History and Theory XIX, 2, 165-85. (Conferência original pronunciada em 1894).

Wolman, B. B. (1960). Contemporary Theories and Systems in Psychology. New York: Harper \& Bros.

William Barbosa Gomes - Psicólogo, Professor de História da Psicologia e Epistemologia, Coordenador do Laboratório de Fenomenologia Experimental e Cognição, orientador de mestrado e doutorado no Instituto de Psicologia da Universidade Federal do Rio Grande do Sul. É pesquisador produtividade 1A do CNPq. Endereço Institucional: Instituto de Psicologia/UFRGS, Rua Ramiro Barcelos, nº 2600, sala 123. CEP 90.034-003. Porto Alegre, RS. Email: gomesw@ufrgs.br 